\title{
The confrontation in the scenario of vaccines, health, and COVID-19
}

\author{
Waldemar de Paula Júnior ${ }^{1,2}$, Felipe Alves Fernandes ${ }^{1}$, Mariléia Chaves Andrade ${ }^{1}$ \\ ${ }^{1}$ Universidade Estadual de Montes Claros (UNIMONTES) - Montes Claros (MG), Brazil \\ 2Programa de Pós-Graduação em Ciências Farmacêuticas, Escola de Farmácia, Universidade Federal de Ouro Preto (UFOP) - Ouro Preto (MG), Brazil
}

ABCS Health Sci. 2020;45:e020013

Access to health, as the right of all and the duty of the State, can be experienced in practice or be nothing more than a dream or fantasy. In fact, it is a matter of contextualization and commitment of all. There are countries where access to health is developed with equality and equity, but in others, it is not treated as a basic condition for survival.

The World Health Organization defends health as a state of complete overall well-being, with good physical, mental, and social conditions. Achieving full physical and mental health depends not only on the possibilities offered by the state, but on individual and collective participation.

Health and well-being can be subsidized by the state in the scope of assistance, social, therapeutic, educational, epidemiological, psychological and assistance actions, associated with quality of life guarantee. But the participation of each citizen is fundamental in all these spheres.

In our daily lives, one of the public actions that fits this context is the vaccination process. Most of the time this is offered by the State, but it is not received with the attention and adhesion it deserves. While part of the population recognizes and exalts the process, another part condemns it. Arguments from both sides are evidenced in various media. Those in favor argue the effectiveness of vaccines, protection, safety, savings for public funds, eradication and disease control, etc.

The vaccination process protects the vaccinated individual, prevents the spread of the disease and reduces the risks of increasing its incidence, impacting on several other scenarios of society. The other aspect points out as disadvantages: risk, inhibition of immune activation in a natural way, lack of tests to guarantee safety, adverse effects, financial and political interests, mandatory vaccination imposed by several governments, among others.

Both sides are vehemently articulated, have a theoretical basis and strong arguments, but should such a serious issue be addressed with this dichotomy? In fact, the observed duality is genuine in the history of vaccination, shaken by the voice of a population revolted by the implementation of vaccination in Brazil; and in the contemporary era, the rush by the population to health entities which run vaccination campaigns, and also by the anti-vaccine movement. However, now the sound of general sense echoes, the consensus that awaits a vaccine against COVID-19, one that will return the routine to the world. Will it be? Will there be groups opposed to vaccination?

The intervention of the government and health entities in a situation like this is delicate, but what about situations such as COVID-19, will it be compulsory? Is it not the obligation of the State to provide its people with guaranteed health? Could this obligation override the convictions of groups against the establishment of conducts for the benefit of an entire population? Is it fair that people in favor of these strategies are at risk because of the non-acceptance of third parties? But the question that does not want to remain silent is: will the denial of the anti-vaccine movement be sustained in times of COVID-19?

All this controversy in a time of a pandemic that kills, that destroys and affects social relations, the economy, and health systems, needs to be reviewed and analyzed, otherwise the state may continue to have the duty to provide health, but the duty will only become a right with a miracle.

How to cite this article: Paula Júnior et al. The confrontation in the scenario of vaccines, health, and COVID-19. ABCS Health Sci. $2020 ; 45:$ e20013. https://doi.org/10.7322/abcshs.45.2020.1655

Corresponding author: Waldemar de Paula Júnior - Universidade Estadual de Montes Claros - Avenida Prof. Rui Braga, s/n - Vila Mauricéia - CEP $39401-089$

- Montes Claros(MG), Brasil -E-mail: wdepaulajr@gmail.com

Declaration of interest: nothing to declare. 